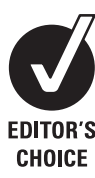

See Editorial, p 217

${ }^{1}$ Department of Population and Family Health Sciences, Johns Hopkins Bloomberg School of Public Health, Baltimore, MD, USA; ${ }^{2}$ Department of International Health, Johns Hopkins Bloomberg School of Public Health, Baltimore, MD, USA; ${ }^{3}$ Epidemiological Surveillance Division, Ministry of Health, Kampala, Uganda; ${ }^{4}$ Institute of Public Health, Makerere University, Kampala, Uganda; ${ }^{5}$ Center for Injury Research \& Policy, Johns Hopkins Bloomberg School of Public Health, Baltimore, MD, USA

Correspondence to: Dr D Bishai, Department of Population and Family Health Sciences, Johns Hopkins Bloomberg School of Public Health, 615 N. Wolfe Street Baltimore, MD 21030, USA; dbishai@jhu.edu

Accepted 18 May 2008

\title{
Cost-effectiveness of traffic enforcement: case study from Uganda
}

\author{
D Bishai, ${ }^{1}$ B Asiimwe, ${ }^{3}$ S Abbas, ${ }^{2}$ A A Hyder, ${ }^{2,5}$ W Bazeyo ${ }^{4}$
}

\section{ABSTRACT}

Background: In October 2004, the Ugandan Police department deployed enhanced traffic safety patrols on the four major roads to the capital Kampala.

Objective: To assess the costs and potential effectiveness of increasing traffic enforcement in Uganda.

Methods: Record review and key informant interviews were conducted at 10 police stations along the highways that were patrolled. Monthly data on traffic citations and casualties were reviewed for January 2001 to December 2005; time series (ARIMA) regression was used to assess for a statistically significant change in traffic deaths. Costs were computed from the perspective of the police department in \$US 2005. Cost offsets from savings to the health sector were not included.

Results: The annual cost of deploying the four squads of traffic patrols (20 officers, four vehicles, equipment, administration) is estimated at $\$ 72,000$. Since deployment, the number of citations has increased substantially with a value of \$327 311 annually. Monthly crash data pre- and post-intervention show a statistically significant $17 \%$ drop in road deaths after the intervention. The average cost-effectiveness of better road safety enforcement in Uganda is $\$ 603$ per death averted or $\$ 27$ per life year saved discounted at 3\% (equivalent to $9 \%$ of Uganda's \$300 GDP per capita).

Conclusion: The costs of traffic safety enforcement are low in comparison to the potential number of lives saved and revenue generated. Increasing enforcement of existing traffic safety norms can prove to be an extremely cost-effective public health intervention in low-income countries, even from a government perspective.

Road traffic injuries kill over a million people annually, $90 \%$ of whom live in low- and middleincome countries. For the world's poorest countries, the problem is expected to worsen in coming decades because the burden of traffic casualties rises in the early stages of economic development with increased motorization of the economy. ${ }^{1-3}$ Wealthy countries in advanced stages of development have been able to control the number of fatal crashes through a variety of countermeasures including occupant protection, better roads, effective trauma systems, and the enforcement of traffic laws. There is hope that low-income countries can implement some of these interventions to control traffic casualties without passively waiting for economic prosperity to propel investments in safer vehicles, roads, and drivers.

There have been few effectiveness studies and fewer cost-effectiveness studies of road-safety interventions in low-income countries. ${ }^{45}$ One of the principal traffic safety measures is the enforcement of traffic safety codes accompanied by media outreach. The European Transport Safety council estimates that if all current road safety laws were enforced in the European Union, deaths and serious injuries could be reduced by up to $50 \%{ }^{6}$ Despite the promise traffic enforcement has shown, there have been few studies to evaluate the effectiveness of traffic law enforcement in lowincome countries. ${ }^{7}$ In Malaysia, more stringent driving codes preceded by an information campaign reduced visibility-related crashes by $29 \%{ }^{8}$ Evidence from a study in Brazil showed a reduction of $25 \%$ in fatalities after a program of enforcement and media was launched. ${ }^{9}$ Legislative changes in Rwanda were followed up in 2003 by a public awareness campaign and stiffer penalties for lack of seatbelt use or failure to wear helmets on motorcycles; WHO reports that the annual number of traffic deaths dropped by about $30 \%$ in the year after the intervention. ${ }^{10}$

No data on the cost-effectiveness of enforcement accompanied any of these studies. Bishai and Hyder developed a cost model and estimated that if the Brazilian traffic law enforcement strategy was applied in sub-Saharan Africa, it could lead to a cost-effectiveness ratio of $\$ 313$ per death averted. ${ }^{5}$ The Bishai and Hyder study was limited in that neither estimates of the cost of the intervention nor the presumed efficacy of the intervention in sub-Saharan Africa could be validated against field measurements because there had been no published studies on this topic from Africa.

Given the magnitude of the global road traffic injury epidemic and the absence of formal evaluations of interventions in low-income countries, this study was designed to evaluate an effort to introduce effective traffic enforcement patrols in Uganda in 2004. The specific objectives of this study were: (1) to examine monthly crash statistics before and after the intervention in order to determine the intervention's potential effect on traffic fatalities; and (2) to compare the costs of the intervention to the number of lives saved in Uganda. This paper hopes to remedy the lack of empirical data from sub-Saharan Africa and to contribute new information on the cost-effectiveness of traffic enforcement for low-income countries.

\section{METHODS}

Prior to 2004, traffic enforcement in Kampala (largest city in Uganda) had primarily consisted of stationing foot patrols on traffic islands in busy intersections. In 2004 the police department acquired four patrol cars and equipped them with speed detecting radar. They hired and trained 20 
Table 1 Balance sheet for highway traffic patrol in Uganda

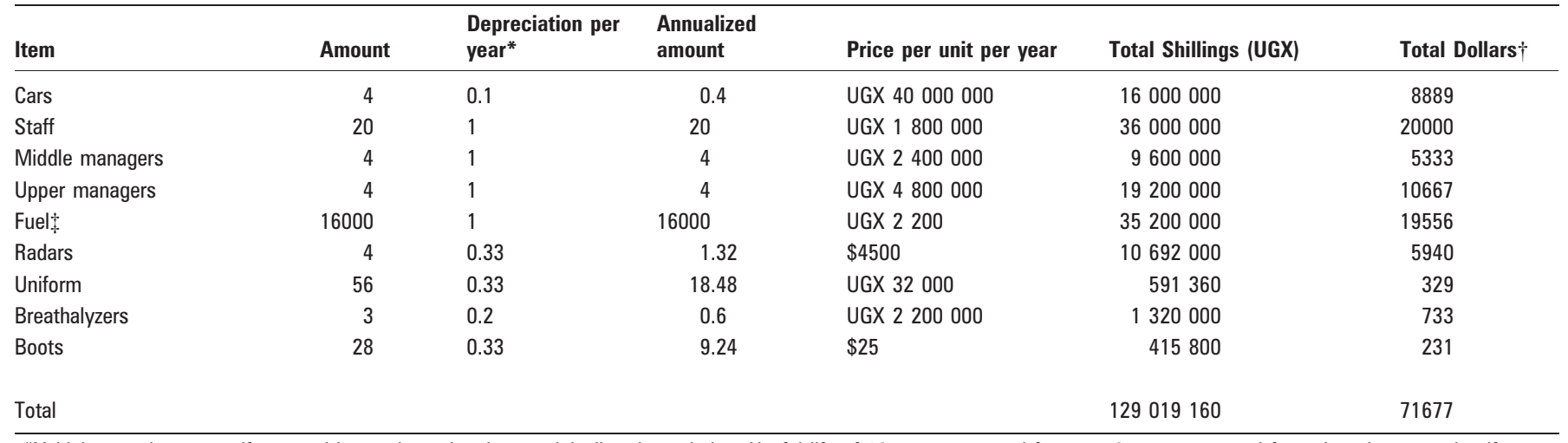

*Vehicles, equipment, uniform, and boots depreciated at straight line depreciation. Useful life of 10 years assumed for cars; 3 years assumed for radars, boots, and uniforms. † Conversion rate is 1800 UGX per US\$ (2005).

$\$ 20$ liters per day per car $\times 4$ cars $\times 200$ working days per year $=16000$ liters per year.

traffic officers to be deployed in mobile teams. In October 2004 they began daily enforcement of traffic regulations on the four main roads leading into Kampala city. The four teams carried out their enforcement efforts each day of the week from 06:00 to $18: 30$. The squads would alter their location on a daily basis and split the task of identifying violators and flagging them to stop, among the members of the team. Each team was trained and equipped to use a Doppler radar to measure speeds, but teams noted delays in servicing the radars that broke down. In practice the violations that officers tended to enforce were unsafe loading, careless driving and speeding (on days when the radar devices were operational). After a motorist was stopped, they could be additionally cited for license violations or alcohol intoxication if these became apparent. Patrol cars were often pressed into good Samaritan service as makeshift ambulances, although neither the vehicles nor the officers were formally outfitted for pre-hospital care.

In September 2005 our research team signed an agreement to collaborate with the Ugandan police to examine the trends in crashes before and after the 2004 intervention. The study was designed to use a simple, pre-/post-intervention, quasi-experimental design using police data. This was supplemented by the use of interview data from police personnel and documentary record review from official vehicle statistics in Uganda.

Beginning in January 2005 researchers traveled to the 10 police garrisons housing the traffic safety officials in charge of

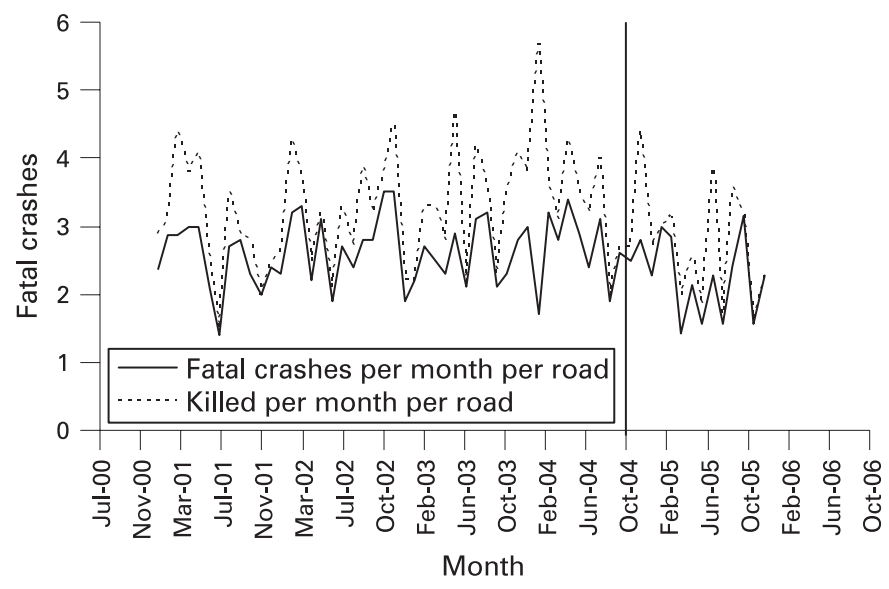

Figure 1 Time series of fatal crashes per month per road and persons killed per month per road. all of the major trunk roads leading into and out of the capital city of Kampala. These roads were also the ones which received the intensive traffic enforcement after October 2004. At each police garrison, the researchers examined the hand-written monthly crash statistics dating back to 2001 and entered them into a standardized template developed for the study in Microsoft Excel. The number of garrison months varied by the type of analysis conducted. A total of 564 out of a potential 600 garrison-months of data were available from the 10 garrisons across 5 years. Three garrisons had not completed their statistics for 2005 so 36 garrison months of observations were not available. Models that controlled for traffic volume data were limited to 348 garrison-months of crash statistics because four garrisons did not have traffic volume data. The following monthly events were recorded by the police: (1) number of fatal crashes; (2) number of people killed; (3) number of total crashes; (4) number of serious crashes; and (5) number of minor crashes. Fatal crashes were defined as dead on the scene, which undercounts the total number of fatalities. This case definition was unaltered before and after the intervention.

Key informant interviews were conducted with police personnel to help establish estimates of costs and potential obstacles to scale-up. Each of these interviews was transcribed and independently analyzed by two member of the research team. Data on road user volume during the study period were based on the official estimates provided by the Ugandan Road Authority in the Ministry of Works of the Government of Uganda. The estimates of road user volume have not been independently validated since no other source of such data is known in the country.

The cost of the traffic safety intervention was determined through ingredients based costing. The key informant interviews were used to determine the numbers of personnel, vehicles, fuel, equipment, administration costs, and prices for each of these items. All capital goods were assumed to undergo straight line depreciation. Based on key informants, the useful service life of vehicles was estimated as 10 years, and useful life of radars, uniforms, and boots, as 3 years. All costs were reported in 2005 Ugandan Shillings and converted to US dollars at an exchange rate of 1800 Shillings per Dollar which was prevailing at the time. Cost estimates are from the perspective of the police department and do not include cost offsets from prevented costs to the medical sector or to owners of wrecked vehicles. Life years saved are discounted at 3\% at baseline, and sensitivity of results is compared to a discount rate of $10 \%$. 
The analysis of monthly crash data focused on determining whether there was a significant change in the numbers of adverse traffic events after the intervention began in October 2004. Three different dependent variables were used in the statistical models: monthly counts of fatal crashes, total crashes, and number killed. The independent variables were a time trend and a dummy variable for observations which occurred after October 2004. The first model examined was a Poisson regression model based on the 564 garrison months of data with a time trend and random effects for each garrison. Annual estimates of traffic volume were available from the central government for six of the garrisons, and Poisson models in which volume was used as an offset variable were fitted to this six-garrison data. The advantage of the Poisson model is its ability to depict the probability of rare events like crashes and fatalities. However, Poisson models do not properly account for the autocorrelation in a monthly series of traffic statistics.

Autoregressive, integrated, moving average (ARIMA) models were also used to control for autocorrelation and seasonality. ${ }^{11}$ In order to implement the ARIMA model, it was necessary to pool data across all garrisons to form monthly counts of events generating a sample size of 60 months of events. Sixteen ARIMA permutations, ranging from 0 to 3 moving average terms and 0 to 3 autoregressive terms were each examined to ensure robustness to distributional assumptions. Besides the intervention timing dummy, all models included a time trend, a dummy for season, and annual measures of traffic volume. General details on ARIMA models are available elsewhere. ${ }^{12}$

Incidence rate ratios were generated using both Poisson and ARIMA models and used to estimate the impact of the intervention in terms of potential lives saved. Using the average age at death of road traffic victims in Uganda and expectation of life for the country, the years of life saved from enforcement were estimated. Finally, the costs of the interventions were used to generate an estimate of the cost-effectiveness of enforcement based on $\$$ per discounted life year saved. This approach is consistent with previously published methods for cost-effectiveness, especially in the recent Disease Control Priorities Project. ${ }^{13}$ The study was an analysis of aggregate secondary data and thus exempted from ethical review by the Johns Hopkins University Committee on Human Research.

\section{RESULTS}

Uganda is a sub-Saharan African country of 25 million people experiencing a rising epidemic of road crashes. The annual number of road crashes for Uganda in 2005 was estimated at 19 528, of which 1732 were fatal and resulted in a total of 2034 deaths. The number of crashes represents a $7 \%$ increase over 2004.

Table 1 shows the estimates of the annual cost of the enforcement operation estimated at 129 million Ugandan Shillings or US\$72 000 in 2005 dollars. Fuel and personnel costs accounted for the largest expenses. The police reported issuing traffic citations in 2005 that would have been worth a total of $\$ 327000$ if there were $100 \%$ collection. None of the key informants in the police department were in a position to estimate the percentage of this revenue that the Ugandan treasury successfully collected. Given the estimate of an average annual volume of 160000 vehicles per year traveling the roads studied in 2005, the enforcement intervention averages roughly $\$ 0.50$ per year per vehicle. The leading three reasons for all violations were speeding (19\%), breach of license $(18 \%)$, and dangerous loading by trucks (16\%). Careless driving was also cited in $14 \%$ of cases.
Data from the Ugandan Ministry of Works indicated an average annual rate of growth of vehicles traveling on each road at $5 \%$ annually. If one uses the official estimates of traffic volume as the denominators to compute annual estimates of crashes per vehicle, then crash rates per 1000 vehicles dropped from a rate of 18.5 crashes per 1000 vehicles pre-intervention to 16.3 crashes per 1000 vehicles post-intervention.

Figure 1 plots the monthly estimates of fatal crashes per month and the number killed per month per road before and after the intervention, showing little seasonality and no perceptible time trend prior to the October 2004 start date. Table 2 shows the results of the statistical analysis. The Poisson regression model shows that the intervention period has a negative association with fatal crashes, total crashes and the number killed. The ARIMA model also shows a similar pattern of lower numbers of events after the intervention. The ARIMA models were robust to multiple distributional assumptions including deleting the seasonality, offset, and time trend terms. Specifying different distributional assumptions for the AR and MA terms showed statistically significant reductions ( $p$ values from 0.01 to <0.10) post-intervention event in 15 of 15 models of fatal crashes, 13 of 15 models of total crashes, and 11 of 15 models of the number killed. The effects in the alternative models were all of similar size, with alternative coefficients typically falling between $5 \%$ higher and lower than the reported coefficients in table 2 .

The incidence rate ratios between pre-intervention and postintervention implied by the Poisson coefficients are $0.82(95 \%$ CI: 0.64 to 1.04$), 0.86$ (95\% CI: 0.79 to 0.93 ), and 0.82 (95\% CI: 0.66 to 1.01) for fatal crashes, total crashes, and number killed. The incidence rate ratios implied by the ARIMA coefficients are 0.745 (95\% CI: 0.58 to 0.91$), 0.845$ (95\% CI: 0.71 to 0.98 ), and 0.727 (95\% CI: 0.51 to 0.94 ) for the same respective outcomes. The incidence rate ratio of 0.73 is equivalent to a 17 percentage point reduction in the number killed.

The reported death count on the roads where the intervention took place was 431 deaths in the year prior to the intervention, representing approximately one fifth of the total annual number of road deaths in the entire country of Uganda. The national toll of road deaths in 2003-04 comprised 5\% drivers, $6 \%$ motorcyclists, $15 \%$ bicyclists, $34 \%$ passengers, and $40 \%$ pedestrians. Applying the incidence rate ratio of 0.727 estimated for the intervention would predict that in a year subsequent to the intervention there would be 313 deaths, or a total of 118 lives saved (95\% CI: 26 to 211).

If one divides the $\$ 72000$ annual program costs by the projected number of lives saved, one derives an estimated cost per death averted of $\$ 603$ (95\% CI: $\$ 336$ to $\$ 2746)$. The average age of road crash victims in Uganda is reported at roughly 27.14 The life expectancy at age 20 is 35 additional years. ${ }^{15}$ With discounting at $3 \%$ the additional 35 years per death averted is worth 22 discounted years for each of the 118 lives saved. Thus, the cost per death averted can be converted to $\$ 27$ (95\% CI: $\$ 15$ to $\$ 118)$ per discounted life year saved. At a $10 \%$ discount the cost per discounted life year saved approximately doubles.

\section{DISCUSSION}

Our finding that traffic enforcement saves lives at a cost of $\$ 27$ per discounted life year saved would rank this intervention among the most cost-effective public health interventions (table 3). The estimate of $\$ 603$ per death averted is higher than the estimate of $\$ 313$ per death averted from traffic enforcement in Africa based on extrapolation and modeling. ${ }^{5}$ The earlier estimate extrapolated a $25 \%$ reduction in fatalities reported 
Table 3 Cost-effectiveness of road traffic injury interventions

\begin{tabular}{lc}
\hline Intervention* & $\begin{array}{l}\text { Cost per DALY } \\
\text { (US\$) }\end{array}$ \\
\hline Improved enforcement (LMIC average) & 5.25 \\
Speed bumps at top 25 percentile dangerous junctions (LMIC & 8.89 \\
average) & 107 \\
Bicycle helmets (China) & 467 \\
Motorcycle helmets (Thailand) & 27 \\
Enforcement in Uganda† & \\
\hline *Data from Disease Control Priorities in Developing Countries, Chapter 39 (www.dcp2. \\
org). \\
†Current study; using discounted life years only. \\
DALY, disability adjusted life year; LMIC, low- and middle-income countries.
\end{tabular}

from Brazil and estimated costs based on a theoretical model of what it might cost to increase traffic enforcement in the average sub-Saharan African country (table 3). The present estimate represents a substantial methodological improvement, because the effects and costs are estimated directly from Ugandan field data.

The success of traffic law enforcement in low-income countries can be markedly different from that in higher-income countries due to differences in the effective functioning of legal and administrative systems. Thus simply improving the laws around speed limits, without substantial investments in enforcement of speed limit laws may have much less effect in a low-income country. ${ }^{16}$ Another example is the challenge of using laws and law enforcement to improve occupant protection vehicles in low-income and middle-income countries when the vehicle stock has few functioning seat belts. ${ }^{17} \mathrm{~A}$ review of the economic analysis of road traffic injury interventions highlighted the fact that studies in high-income countries assumed enforcement and compliance; while this could not be the case in low-income countries where the costs of such enforcement might be substantial. ${ }^{4}$ This study provides one case study from Uganda to empirically support that premise.

An obvious limitation of this work is that benefit estimates neglect all impact of the intervention on non-fatal injury; and the cost estimates neglect all cost offsets due to savings to the medical system. If each death averted also averted medical costs and vehicular damage in excess of $\$ 603$ it would make the intervention cost-saving from the perspective of society. It seems plausible that fatal crashes would typically be associated with vehicular damage costs of at least this magnitude, but the data collected did not assess these costs.

The events that were studied are subject to under-reporting, because many crashes, even serious ones, are never reported to the police. The method of comparing pre- and post-intervention crash rates is vulnerable to bias from secular trends other than the enforcement intervention that could have been responsible for lowering the number of crashes. However, according to the police that were interviewed and the Ugandan research team, there were no other major interventions on these roads or in the popular media or educational system that coincided with the timing of the intervention. There were no interventions targeted toward improved pre-hospital care on these roads other than the presence of the police patrols themselves.

\section{IMPLICATIONS FOR PREVENTION}

To put the cost-effectiveness ratios in context, one can compare the $\$ 27$ per life year saved from traffic law enforcement to other routinely accepted health interventions in sub-Saharan Africa (table 3). The global public health community has made it a high priority to scale up the distribution of antiretroviral 


\section{Key points}

- Road crashes kill 1.2 million people every year, with most deaths occurring in low- and middle-income countries.

- Little is known about the effectiveness or cost-effectiveness of traffic enforcement in the developing world except for results based on simulation models that have not been validated.

- This study offers primary data showing a $17 \%$ reduction in traffic fatalities in the year after the Ugandan government began a program to scale up traffic enforcement on the main roads around the capital.

- The program cost US\$72000 per year, which amounts to roughly \$27 per life year saved, making it one of the most cost-effective public health investments in a low-income country like Uganda.

- Such empirical studies are needed in the developing world to inform national and local policy choices that prioritize road safety investments for national health and development.

therapy for HIV in Uganda, and this intervention would cost $\$ 600$ per life year saved..$^{18}$ Although there is no universal cut-off that determines when an intervention would not be considered cost-effective, the Commission on Macroeconomics and Health defines interventions with a cost-effectiveness ratio that is less than per capita GDP as very cost-effective. ${ }^{19}$ Because GDP per capita in Uganda is estimated at $\$ 300$ international dollars in 2006, the cost-effectiveness ratio per life year saved for traffic safety enforcement is only 9\% of GDP per capita. Few health interventions are comparatively as cost-effective. These results show that some interventions undertaken outside the health sector can be extremely efficient investments in health. Policy makers concerned with improving health should examine improved traffic safety as a promising way to accelerate progress toward public health.

Acknowledgements: The authors wish to thank the Johns Hopkins Center for Injury Research and Policy (supported by Centers for Disease Control and Prevention Grant \#R49CCR302486). We are grateful for the assistance of Traffic and Road Safety
Commissioner Kasiima M Steven, Assistant Inspector of Police John Asobasi, Col Ahmbisibwe Wilson, and the police officers of the Kampala Traffic and Road Safety Unit. Helpful comments were contributed by Dick Morrow and Tim Baker.

Competing interests: None.

\section{REFERENCES}

1. Bishai D, Qureshi A, James $P$, et al. National Road Fatalities and Economic Development. Health Economics 2005;15:65-81.

2. van Beeck EF, Borsboom GJ, Mackenbach JP. Economic development and traffic accident mortality in the industrialized world, 1962-1990. Int J Epidemiol 2000;29:503-9.

3. Kopits E, Cropper M. Traffic fatalities and economic growth. Accid Anal Prev 2005;37:169-78.

4. Waters $\mathbf{H}$, Hyder A, Phillips T. Economic evaluation of interventions to reduce road traffic injuries - a review of literature with applications to low and middle income countries. Asia Pacific Journal of Public Health 2004;16:23-31.

5. Bishai D, Hyder AA. Modeling the cost effectiveness of injury counter measures in lower and middle income countries: opportunities and challenges [abstract]. Cost Effectiveness and Resource Allocation 2006;4:2

6. European Transport Safety Council. Police enforcement strategies to reduce traffic casualties in Europe. Brussels: European Transport Safety Council (Injury), 1999.

7. Ameratunga S, Hijar M, Norton R. Road-traffic injuries: confronting disparities to address a global-health problem. Lancet 2006:367:1533-40.

8. Radin UR, Mackay MG, Hills BL. Modelling of conspicuity-related motorcycle accidents in Seremban and Shah Alam, Malaysia. Accid Anal Prev 1996;28:325-32.

9. Poli de Figueiredo LF, Rasslan S, Bruscagin V, et al. Increases in fines and driver licence withdrawal have effectively reduced immediate deaths from trauma on Brazilian roads: first-year report on the new traffic code. Injury 2001:32:91-4.

10. World Health Organization. Rwanda's road-safety transformation. Bulletin of the World Health Organization 2007:85:421.

11. Box G, Jenkins G. Time series analysis: forecasting and control. San Francisco: Holden Day, 1984.

12. Diebold F. Elements of forecasting, 3rd edn. Cincinnati: Southwestern, 2004.

13. Mulligan JL, Fox-Rushby J, Adam T, et al. Unit Costs of health care inputs in low and middle income regions. DCPP Working Paper 9, 2003

14. Andrews CN, Kobusingye OC, Lett R. Road traffic accident injuries in Kampala. East Afr Med J 1999;76:189-94.

15. World Health Organization. Life tables for WHO member states, Uganda 2005 Geneva: World Health Organization, 2005.

16. Afukaar FK. Speed control in developing countries: issues, challenges and opportunities in reducing road traffic injuries. Inj Control Saf Promot 2003;10:77-81.

17. Forjuoh SN. Traffic-related injury prevention interventions for low-income countries Injury Control and Safety Promotion 2003;10:109-18.

18. Bishai D, Colchero MA, Durack D. The cost effectiveness of antiretroviral treatment strategies in resource-limited settings. AIDS 2007;21:1333-40.

19. World Health Organization. Macroeconomics and health: investing in health for economic development: report of the Commission on Macroeconomics and Health. Geneva: World Health Organization, 2001.

\section{Seatbelt use enforcement in Iraq}

Traffic police in Iraq will soon begin issuing tickets to drivers who violate the nation's seatbelt law. The mandate applies only to drivers, not passengers; violators will be fined 15000 dinars (about US\$12.50, €8). Despite more urgent problems on Iraq's roads, officials say the enforcement of such a law has a unique purpose. "It is part of the healing process of this country and of Baghdad to enforce the law, law by law," said Brigadier General Zuhair Abada Mraweh, traffic commander for Bagdad's Rusafah district. "The citizens are learning the laws step by step. We have applied all the laws concerning traffic, so it's time for the seatbelt law to be practiced," he said. Traffic police have been a constant presence on Iraq's roads during the last 5 years. But during that time, a high import tax on automobiles was lifted, flooding the country with new drivers. The number of traffic crashes is unknown, but enforcing the seatbelt law could reduce injuries by $70 \%$, said Mraweh. Drivers agreed that enforcement of the law would be a positive thing. "It is a symbol of civilization," said taxi driver Ahmed Wahayid.

From CDC Public Health Law News, Wednesday 23 April 2008. Contributed by Jeanette Hudson and Brian Johnston. 